\title{
Isolation and Identification of Candida Species by Using Chrome Agar from Various Clinical Samples
}

\author{
Dr. Amita Arya ${ }^{1 *}$, Dr. Naimshree ${ }^{2}$ \\ ${ }^{1}$ Assistant Professor, Department of Microbiology, Career Institute of Medical Sciences, Lucknow, Uttar Pradesh, India \\ ${ }^{2}$ PG Student, Department of Microbiology, Career Institute of Medical Sciences, Lucknow, Uttar Pradesh, India
}

DOI: $10.36348 /$ sipm.2020.v05i06.004

| Received: 07.06.2020 | Accepted: 15.06.2020 | Published: 24.06.2020

*Corresponding author: Dr. Amita Arya

\section{Abstract}

Candida is yeast like fungus and ubiquitous human commensal. They become pathogens and cause infections when the host's resistance to infection is lowered either locally or systemically [1]. The present study was conducted to evaluate the advantages of CHROM agar from various clinical samples for Isolation of Candida. In this study Candida albicans was isolated in $48.4 \%$ species. 248 samples were collected, where Urine sample was the most common sample (68.1\%) followed by Pus (13.3\%) and blood (14.3\%). The percentage of other samples was less than $4.3 \%$. Candida culture was positive in $25 \%$ of the samples. The most common organism isolated among bacteria was E.coli (10.2\%). Growth on Saboraud dextrose agar culture was positive in $25 \%$ of the samples. Gram staining was positive in $25 \%$ of the samples. Germ tube test was positive in $51.6 \%$ of the samples. Candia albicans was the most common species isolated (51.6\%) followed by C.tropicalis (38.7\%), C.kruseik (8.1\%) and C.glabrata (1.6\%). Non-Candia albicans was isolated in $48.4 \%$ species.

Keywords: human commensal, pathogens, systemically, bacteria, species

Copyright @ 2020: This is an open-access article distributed under the terms of the Creative Commons Attribution license which permits unrestricted use, distribution, and reproduction in any medium for non-commercial use (NonCommercial, or CC-BY-NC) provided the original author and sources are credited.

\section{INTRODUCTION}

Candida is yeast like fungus and ubiquitous human commensal. They become pathogens and cause infections when the host's resistance to infection is lowered either locally or systemically [1]. Candida is a polymorphic fungus. It is a Gram positive, oval, budding yeast cell that produces pseudohyphae both in culture and in tissues and exudates. Candida albicans is the most common cause of candidiasis accounting for about $60-80 \%$ of infections. An increase in prevalence of non-albicans species has been noted during last decades[2,3]. There is growing evidence suggesting a role for increasing use of azole agents in this epidemiological shift. Several of these non-albicans Candida species (e.g., C. glabrata and $C . \quad$ krusei) exhibit resistance to traditional triazole antifungals like fluconazole, and may also demonstrate cross-resistance to newer triazoles[[4]. Characterization to species level helps to identify those strains which might be intrinsically resistant to some antifungal agents[5,6]. Speciation of Candida isolates is conventionally done by germ tube test, sugar assimilation and fermentation tests. Newer methods include CHOM agar, API system, Vitek 2 ID system and molecular methods [7]. Since API system, Vitek 2ID system and molecular techniques are expensive, use of CHROM agar for species differentiation would be of benefit for easy and rapid speciation[8]. They contain chromogenic substrates that react with enzymes secreted by microorganismsproducing colonies with various pigmentation. These enzymes are species specific, allowing organisms to be identified to the species level by their colour and colony characteristics [9].

The genus candida contains more than 200 species only about 8 medically important species of candida are found in men-C. albicans, C. stellatiodea, C. tropicalis, C. krusei, C. guilliermondii, C. viswanathii, C. glabrata and C. parapsilosis of which $\mathrm{C}$. albicans is responsible for most $(90 \%)$ of the human infections[10].

Systemic Candida infections are associated with a high mortality rate $(38 \%)$ and prolonged hospital stay. Presently, C. albicans accounts for $\sim 80 \%$ of all nosocomial Candida infections, although a noticeable shift toward Candida species other than C. albicans has been observed, which is important because of intrinsic or acquired antifungal resistance in several of these species. These non-albicans species of Candida yeasts include, in order of typical decreasing frequency, 
Candida glabrata, Candida parapsilosis, Candida tropicalis, and Candida krusei, among others [11].

Over the last few decades, there has been an increase in the incidence of candidiasis caused by other Candida species (non-albicansCandida) such as Candida dubliniensis, Candida glabarta, Candida krusei, Candida tropicalis, and Candida. Parapsilosis $[12,13]$.

The present study was conducted to evaluate the advantages of CHROM agar from various clinical samples for Isolation of Candida.

\section{MATERIAL AND METHODS}

This study was conducted in the Department of Microbiology, HIMS, Safedabad, Barabanki, U.P from Jan. 2016 to Dec. 2016 (One year).The study was conducted on the clinical samples Blood, Urine, pus, sputum, catheter tip and swabs (Vaginal, ear, throat) from OPD and IPD received in Microbiology Department Primarily catering rural area of Barabanki. Patients were of low socio economic class.

Study Design: Hospital BaseCross sectional study.

Sample Size: Total no. of 248 samples collected including Blood, Urine, pus, sputum, catheter tip and swabs (Vaginal ear throat),stool

\section{Inclusion Criteria}

Candida species isolated from clinical samples received in the Department of Microbiology from OPD and IPD patients of HIMS.

\section{Exclusion Criteria \\ i. Samples containing normal flora (commensals). \\ ii. Contamination in culture plate and showing polymicrobial growth.}

\section{METHODOLOGY Sample Collection}

All clinical samples from hospital received in the Microbiology laboratory in the form of urine, blood, pus, stool, sputum, body fluids, vaginal swabs, throat swabs, ear swabs etc.

\section{Sample processing \\ Urine and catheter tip}

The samples were processed by culturing on Cystine lactose electrolyte deficient agar (CLED) and incubated at $37^{0} \mathrm{C}$ for $18-24$ hours.

\section{Blood}

The samples were initially cultured in BHI broth and subculture was done on Blood agar, Mac Conkey agar incubated aerobically at $37^{0} \mathrm{C}$ for $18-24$ hour.

\section{Pus (centrifugated body fluid) and swab}

Direct plating was done on Mac Conkey agar and Blood agar and inoculated into RCM broth aerobically incubated for $18-24$ hours at $37^{\circ} \mathrm{C}$, further subculturewas done on Mac Conkey agar and Blood agar incubated at $37^{0} \mathrm{C}$ for $18-24$ hours.

\section{Stool}

The samples were processed by culturing on Deoxycholate citrate agar (DCA) and Salenite F broth incubated at $37^{\circ} \mathrm{C}$ for 18 to 24 hour.

\section{Sputum}

Samplewere cultured on chocolate agar, $\mathrm{CO}_{2}$ incubater inside candle jar. Further Subculture was done from in RCM after $24 \mathrm{hrs}$.

- Primary gram staining was done whenever required.

- All bacterial growth was identified by gram's staining, biochemical test, enzyme test, and AST.

\section{Chrome agar}

For speciation of candida commercially available Hicrome candida differential agar (by Himedia Laboratories) was used.

Procedure of inoculation- 3-5 candida colony was taken with help of inoculating loop from SDA plate/tube and cultured on chrome agar plate. Incubated at $30^{\circ} \mathrm{C}$ for 48 hour.

Interpretation For speciation-was done on the basis of colour production and colony morphology.

\begin{tabular}{|l|l|l|l|}
\hline SN & Candida Species & Colour & Colony morphology \\
\hline 1 & C albicans & Light Green & Smooth \\
\hline 2 & C. tropicalis & Steel Blue & Raised \\
\hline 3 & C. Krusei & Purple & Fuzzy \\
\hline 4 & C. parapsilosis & Pink & Smooth \\
\hline 5 & C. glabrata & White & \\
\hline 6 & C. lusitaniae & Pink & \\
\hline 7 & C. nivariensis & Cream to white & \\
\hline 8 & C. guilliermondii & Light Pink & \\
\hline
\end{tabular}




\section{STATISTICAL ANALYSIS}

The results are presented in mean \pm SD and percentages. The categorical / dichotomous variables were compared by using Chi-square test. The Unpaired t-test was used to compare continuous variables between two strata. The p-value $<0.05$ will be considered significant. All the analysis will be carried out on SPSS 16.0 version (Chicago, Inc., USA).

\section{OBSERVATIONS AND RESULTS}

The present study was conducted in the Department of Microbiology, Hind Institute of Medical Sciences, Safedabad Barabanki with the objective to isolate and identify the Candida species by using
Chrome Agar from various clinical samples. A total of 248 patients were included in this study. The conclusions of this study are as follows:

Table-1: Distribution of Candida albicans and Non

\begin{tabular}{|} 
albicans Candida isolates \\
\hline Candid Species & No & $\%$ \\
\hline Albicans & 32 & 51.6 \\
\hline Non-albicans & 30 & 48.4 \\
\hline
\end{tabular}

Table 1 \& Figure 1 show the distribution of according to candida albicans and Non albicans. Non Candida albicans was isolated in $48.4 \%$ species.

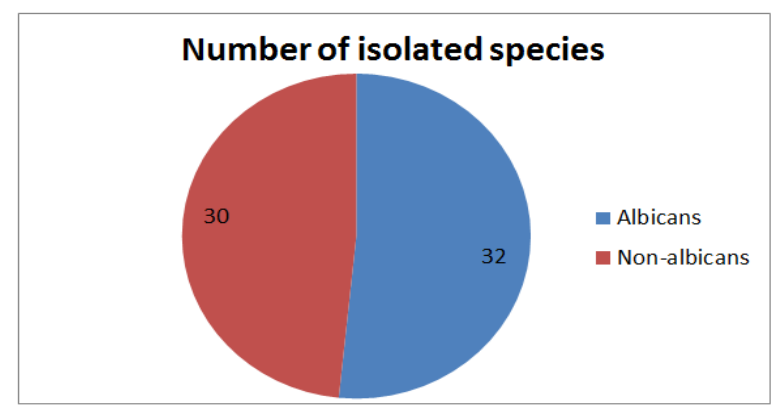

Fig-1: Candida albicans and Non albicans Candida isolates

Table-2: Type of Samples

\begin{tabular}{|c|c|c|c|}
\hline SN & Type of sample & NO & Percentage \\
\hline 1 & Urine sample & 168 & 68.1 \\
\hline 2 & Pus sample & 34 & 13.2 \\
\hline 3 & Blood sample & 35 & 14.3 \\
\hline 4 & Other samples & 11 & 4.4 \\
\hline \multicolumn{2}{|c|}{ Total } & \multicolumn{2}{|c|}{248} \\
\hline
\end{tabular}

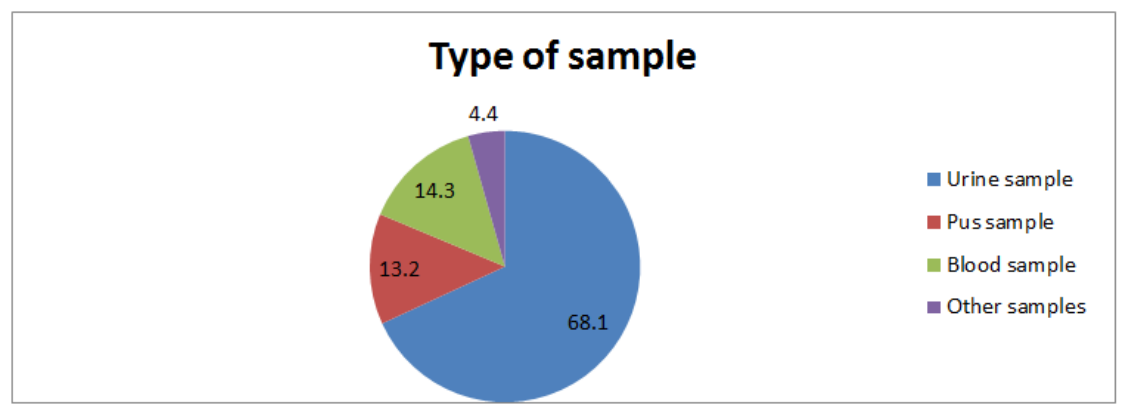

Fig-2: Type of Samples

Urine sample was the most common sample (68.1\%) followed by Pus $(9.7 \%)$ and blood $(9.3 \%)$. The percentage of other samples was less than $5 \%$.

Table-3: Distribution of sample

\begin{tabular}{|c|l|c|c|}
\hline SN & \multicolumn{1}{|c|}{ Species } & No of sample & Percentage \\
\hline 1 & Candida culture & 62 & $25 \%$ \\
\hline 2 & bacteria was E.coli & 25 & 10.2 \\
\hline 3 & Growth on Saboraud dextrose agar culture & 62 & $25 \%$ \\
\hline 4 & Gram staining & 62 & $25 \%$ \\
\hline 5 & Germ tube test & 128 & $51.6 \%$ \\
\hline 6 & Candia albicans & 128 & 51.6 \\
& C.tropicalis & 96 & 38.7 \\
& C.kruseik & 20 & 8.1 \\
& C.glabrata & 4 & 1.6 \\
\hline 7 & Non-Candia albicans was isolated & 120 & $48.4 \%$ species \\
\hline
\end{tabular}


Table-4: Distribution of candida species

\begin{tabular}{|l|c|c|c|}
\hline Candid species & Colour on chrome agar & No $(\mathbf{n = 6 2})$ & $\mathbf{\%}$ \\
\hline C-albicans & Light green & 32 & 51.5 \\
\hline C-glabrata & White & 1 & 1.6 \\
\hline C Kruseik & Purple & 5 & 8.1 \\
\hline C-tropicalis & Blue & 24 & 38.7 \\
\hline
\end{tabular}

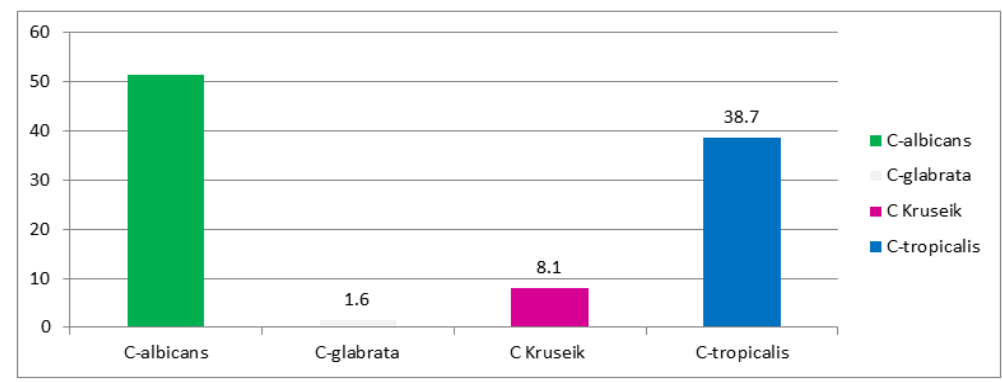

Fig-4: Distribution of candida species

Table 4 \& Figure 4 show the distribution of patients according to candid species. Candida albicans was the most common species isolated (51.6\%) followed by C.C-tropicalis (38.7) C.kruseik (8.1\%) and C. glabrata $(1.6 \%)$.

\section{DISCUSSION}

The present study was conducted in the Department of Microbiology, Hind Institute of Medical Sciences, Safedabad Barabanki with the objective to isolate and identify the Candida species by using Chrome Agar from various clinical samples.

Potential clinical importance of species level identification has been recognized as Candida species differ in the expression of virulence factors and antifungal susceptibility [14]. Candida species also have a direct impact on the choice of empirical antifungal therapy and clinical outcome. Non-albicans candida species are on the rise due to increasing immunocompromised condition. In the present study, C. albicans is predominant $(51.6 \%)$. Predominance of C. albicans was also seen in a study by Manjunath et al. [15] However, higher incidence of non-albicans candida ranging from $54-74 \%$ have been seen in numerous studies[16, 17]. Among the non-albicans candida, $C$. tropicalis is reported to be the most predominant species. In this study, also $C$. tropicalis was the most common non-albicans species.

As a common and widespread opportunistic yeast pathogen, Candida species account for $8-10 \%$ of all nosocomial bloodstream infections [18-20]. In this study, $C$. tropicalis was the most prevalent strain found in blood samples (14.3\%), whereas $C$. albicans, C.tropicalis, C. kruseik, C.glabrata were isolated from $51.6 \%, 38.7 \%, 8.1 \%$ and $1.6 \%$ of samples. These data are consistent with previously published results showing that C. glabrata, C. parapsilosis, C. tropicalis, and other non-albicans Candida (NAC) species have been recovered with increasing frequency [21, 22]. It is therefore interesting that $C$. tropicalis infections have increased since 2003, whereas infections due to all other non-albicans species have been decreasing [23]. In a study performed at the University Hospital of the Federal University of Mato Grosso do Sul (HU-UFMS), NAC samples were recovered more frequently from blood culture samples than $C$ albicans and $C$ parapsilosis [24]. It was also demonstrated that $39 \%$ of surveyed blood cultures harboured NAC [25].

Overall, the speciation of Candida is important to provide a data base for given area of study. The choice of anti fungal drugs is also dependent on the species of Candida. This information will help us to recognize the emerging fungal pathogen and increasing drug resistance. The present study also highlights the need for periodic surveillance of antifungal susceptibility pattern of the prevalent Candida species, as it would enlighten the judicious use of antifungal drugs in patients, thus preventing the emergence of drug resistance.

\section{CONCLUSION}

In this study Candida albicans was isolated in $48.4 \%$ species. 248 samples were collected, where Urine sample was the most common sample $(68.1 \%)$ followed by Pus (13.3\%) and blood (14.3\%). The percentage of other samples was less than $4.3 \%$. Candida culture was positive in $25 \%$ of the samples. The most common organism isolated among bacteria was E.coli (10.2\%). Growth on Saboraud dextrose agar culture was positive in $25 \%$ of the samples. Gram staining was positive in $25 \%$ of the samples. Germ tube test was positive in $51.6 \%$ of the samples. Candia albicans was the most common species isolated $(51.6 \%)$ followed by C. tropicalis (38.7\%), C.kruseik $(8.1 \%)$ and C. glabrata $(1.6 \%)$. Non-Candia albicans was isolated in $48.4 \%$ species.

\section{REFERENCES}

1. Anaissie, E.J., McGinnis, M.R., Pfaller, M.A. (2009). Eds. Clinical Mycology, 2nd edn. Philadelphia, Churchill Livingstone.

2. Makanjuola, O., Bongomin, F., \& Fayemiwo, S. A. (2018). An Update on the Roles of Non- 
albicansCandida Species

Vulvovaginitis. Journal of fungi (Basel, Switzerland), 4(4), 121.

3. Oberoi, J.K., Wattal, C., Goel, N., Raveendran, R., Datta, S., Prasad, K.(2012). Non-albicans Candida species in blood stream infections in a tertiary care hospital at New Delhi, India. Indian J Med Res, 136(6):997- 1003.

4. Magill, S. S., Shields, C., Sears, C. L., Choti, M., \& Merz, W. G. (2006). Triazole cross-resistance among Candida spp.: case report, occurrence among bloodstream isolates, and implications for antifungal therapy. Journal of clinical microbiology, 44(2), 529-535.

5. Marie, C., \& White, T. C. (2009). Genetic basis of antifungal drug resistance. Current fungal infection reports, 3(3), 163-169.

6. Marichal, P., Koymans, L., Willemsens, S., Bellens, D., Verhasselt, P., Luyten, W., ... \& Bossche, H. V. (1999). Contribution of mutations in the cytochrome P450 14 $\alpha$-demethylase (Erg11p, Cyp51p) to azole resistance in Candida albicans. Microbiology, 145(10), 2701-2713.

7. Jain, N., Mathur, P., Misra, M. C., Behera, B., Xess, I., \& Sharma, S. P. (2012). Rapid identification of yeast isolates from clinical specimens in critically ill trauma ICU patients. Journal of laboratory physicians, 4(1), 30.

8. Aal, A. M. A., Taha, M. M., El-Mashad, N., \& ElShabrawy, W. (2007). Antifungal susceptibility testing: New trends. Egyptian Dermatology Online Journal, 3, 1 .

9. Horvath, L. L., Hospenthal, D. R., Murray, C. K., \& Dooley, D. P. (2003). Direct isolation of Candida spp. from blood cultures on the chromogenic medium CHROMagar Candida. Journal of clinical microbiology, 41(6), 2629-2632.

10. Magalhães, Y. C., Bomfim, M. R. Q., Melônio, L. C., Ribeiro, P., Cosme, L. M., Rhoden, C. R., \& Marques, S. G. (2015). Clinical significance of the isolation of Candidaspecies from hospitalized patients. Brazilian Journal of Microbiology, 46(1), 117-123.

11. Pfaller, M. A. (1996). Nosocomial candidiasis: emerging species, reservoirs, and modes of transmission. Clinical diseases, 22(Supplement_2), S89-S94.

12. Eliopoulos, G. M., Perea, S., \& Patterson, T. F. (2002). Antifungal resistance in pathogenic fungi. Clinical Infectious Diseases, 35(9), 10731080 .

13. Khadka, S., Regmi, P., Giri, S., Shah, P. K., \& Mishra, S. K. (2016). Identification of Candida species using CHROM agar. International Journal of Medicine and Biomedical Sciences, 1(3), 10-13.
14. Murray, M. P., Zinchuk, R., \& Larone, D. H. (2005). CHROMagar Candida as the sole primary medium for isolation of yeasts and as a source medium for the rapid-assimilation-of-trehalose test. Journal of clinical microbiology, 43(3), 12101212.

15. Manjunath, V., Vidya, G.S., Sharma, A., Prakash, M.R., Murugesh, N.(2012). Speciation of Candida by Hi-Chrom agar and sugar assimilation test in both HIV infected and non-infected patients. Int $\mathrm{J}$ Biol Med Res, 3(2):1778-82.

16. Vijaya, D., Harsha, T. R., \& Nagaratnamma, T. (2011). Candida speciation using chrom agar. $J$ Clin Diagn Res, 5(4), 755-757.

17. Adhikary, R., Joshi, S.(2013). Species distribution and anti-fungal susceptibility of candidemia at a multi super-speciality center in Southern India. Ind J Med Microbiol, 29:309-11.

18. Lundston, T., Sobel, J. (2001). Nosocominal Candidúria: A Review. Clin Infect Dis 32:16021607.

19. Colombo, A. L., Matta, D. D., Almeida, L. P. D., \& Rosas, R. (2002). Fluconazole susceptibility of Brazilian Candida isolates assessed by a disk diffusion method. Brazilian Journal of Infectious Diseases, 6(3), 118-123.

20. França, J. C. B., Ribeiro, C. E. L., \& de QueirozTelles, F. (2008). Candidemia in a Brazilian tertiary care hospital: incidence, frequency of different species, risk factors and antifungal susceptibility. Revista da Sociedade Brasileira de Medicina Tropical, 41(1).

21. Krcmery, V., \& Barnes, A. J. (2002). Non-albicans Candida spp. causing fungaemia: pathogenicity and antifungal resistance. Journal of hospital infection, 50(4), 243-260.

22. Eliopoulos, G. M., Perea, S., \& Patterson, T. F. (2002). Antifungal resistance in pathogenic fungi. Clinical Infectious Diseases, 35(9), 1073 1080.

23. Yap, H. Y., Kwok, K. M., Gomersall, C. D., Fung, S. C., Lam, T. C., Leung, P. N., ... \& Joynt, G. M. (2009). Epidemiology and outcome of Candida bloodstream infection in an intensive care unit in Hong Kong. Hong Kong Med J, 15(4), 255-261.

24. Xavier, P. C. N., Chang, M. R., Nunes, M. O., Palhares, D. B., Silva, R. A., Bonfim, G. F., \& Almeida Júnior, N. F. (2008). Candidemia neonatal, em hospital público do Mato Grosso do Sul. Revista da Sociedade Brasileira de Medicina Tropical, 41(5), 459-463.

25. Hanh, R. C., Prado, K. S., \& Dias, L. B. (2008). Candidíase em um hospital universitário matogrossense: incidência, freqüência das diferentes espécies e susceptibilidade aos antifúngicos. Prática Hospitalar, 10, 69-72. 